\title{
THE USE OF TRANQUILLIZERS
}

\author{
By A. R. MaY, M.B., D.P.M. \\ Chief Assistant, Dept. of Psychiatry, Westminster Hospital
}

\section{Introduction}

A whole series of new drugs has become available for the treatment of certain forms of psychiatric illness and the interest they have evoked is reflected in the hundreds of publications on their use and action and in the pharmaceutical research which continually adds some new compound to the already formidable list of tranquillizers. These drugs are characterized by their ability to produce sedation without hypnosis and Fabing (1955a) has suggested the term ' ataraxy' to denote the peace of mind and freedom from mental disturbance which it is claimed they produce.

Although the indications for the use of reserpine and chlorpromazine, which have been in largescale use for three or four years, are becoming clearer, the position with regard to the newer tranquillizers is by no means certain, and it seems appropriate to make some critical review of the information at present available concerning the mode of action and clinical uses of these drugs.

\section{Site and Mode of Action}

Research on the neurophysiological action of chlorpromazine and reserpine has been summarized by Hinwich (1955). It seems that these drugs exert a central action on the hypothalamus and also on the mesendiencephalic alerting system (Rinaldi and Himwich, I955) which comprises the reticular formation of Moruzzi and Magoun (1949) and the thalamic diffuse cortical projections of Jasper (1949). By depressing the hypothalamus they lower basal metabolism, body temperature and blood pressure and they also influence the anterior pituitary, causing disturbance of hormonal balance, which leads to lactation and amenorrhea in some women. In general, they thus produce parasympathomimetic effects and, in addition, chlorpromazine has a peripheral blocking action on sympathetic ganglia.

Stimulation of the mesendiencephalic alerting system produces characteristic low amplitude rapid waves in the E.E.G. Reserpine evokes a similar pattern of stimulation (though at the same time depressing the hypothalamus), while chlorpromazine in small doses blocks this pattern, but in large doses reverses its action and stimulates the alerting system. A side reaction of this stimulation is the development of a Parkinsonian syndrome, such as occurs when the reticular system is released from control by lesions of the basal ganglia.

Himwich et al. (1956) suggest that depression of the mesendiencephalic system has a calming effect on disturbed behaviour and postulate that this action, characteristic of chlorpromazine, might assist in the therapeutic screening of new phenothiazine derivatives.

An interesting aspect of recent research on tranquillizing drugs has been their effect on the action of indole hallucinogens. Some of these drugs (chlorpromazine and azacyclonol) are said to ameliorate the 'model psychosis' produced by hallucinogenic agents (e.g. lysergic acid diethylamide [LSD] and mescaline) in normal subjects. Considerable speculation centres on the role of serotonin (5-hydroxytryptamine), a non-hallucinogenic indole normally present in brain, which is said to antagonize the action of LSD (Gaddum, I953). It is suggested (Wooley and Shaw, r954a, b) that serotonin concentration influences the development of some mental disorders. The precise mechanism is still undetermined, but it seems possible that tranquillizing drugs may alter behaviour by their influence on serotonin (Himwich, 1955).

\section{Classification}

The tranquillizing drugs are difficult to classify by chemical structure, although phenothiazine derivatives form a homogeneous group. Their neurophysiological properties might be used as a basis for grouping, but at present it seems best to follow a clinical classification as suggested by Lieberman and Vaughan (1956).

They may thus be broadly divided into the more powerful tranquillizers, which are principally of use in psychoses, and the less powerful, which are used mainly in neuroses.

\section{More Powerful Tranquillizers \\ Phenothiazine Derivatives \\ Chlorpromazine was the first of these compounds}


to be utilized in psychiatric treatment by Delay and his co-workers. Its action is typical of other members of this group and its main use is in the reduction of tension and the control of psychomotor over-activity. An enormous literature has accumulated round chlorpromazine and, while most authors agree that its value in neurotic illness is limited save in tension states (Garmany et al., 1954), and that it has little effect on depression, there is considerable evidence supporting its usefulness in disturbed over-active and aggressive psychotics. Many workers (e.g. Bird et al., 1955) report that electro-convulsion therapy (E.C.T.) has been superseded as a method of treatment in these cases. The majority of opinion holds that chlorpromazine is of benefit only in symptomatic control, but some workers (Labhardt, I954; Lomas, 1955) consider that it alters the content of schizophrenic psychosis, and in some hospitals it has replaced insulin as a method of treatment of schizophrenia (Boardman et al., 1956; Bowes, 1956). Chlorpromazine has also proved valuable in the management of senile agitated patients and in disturbed over-active children.

The initial dosage of chlorpromazine is 25 to $50 \mathrm{mg}$. three or four times daily, but intramuscular injection of 50 to $100 \mathrm{mg}$. is indicated for rapid control of disturbed behaviour. Therapeutic effects in psychotic patients often require a high maintenance dosage and this may be in the region of $800 \mathrm{mg}$. daily (Freeman et al., 1956).

The complications of chlorpromazine therapy have been reviewed by Cohen (1956). The majority are of minor importance and seem due to action on the hypothalamus and autonomic nervous system. They include drowsiness, hypotension, constipation, menstrual disorders and lactation. A second group of allergic phenomena covers a variety of skin rashes ranging from erythema to generalized exfoliative dermatitis. Photosensitivity is fairly common in patients exposed to sunlight and contact dermatitis occurs in sensitized nursing staff. Severe toxic effects include jaundice in about r.4 per cent. of cases (Kinross-Wright and Moyer, 1956). Chronic alcoholism, liver damage, pregnancy, vomiting or anorexia may predispose to this complication, which usually occurs in the first four weeks of therapy and which takes the form of biliary obstruction with bile plugs in intralobular canaliculi. Jaundice usually disappears in a week, even though chlorpromazine therapy is continued, but most workers recommend stopping the drug temporarily. On heavy dosage Parkinsonism sometimes develops, but this is reversible on decreasing the dosage. Agranulocytosis is a rare and sometimes fatal complication and a possibility which requires vigilance, especially when employing high dosages for a long period. Ayd (1956) believes that the skin lesions, hepatitis and agranulocytosis are manifestations of drug sensitivity resulting from the chemical structure of chlor- $\frac{\Phi}{d}$ promazine.

Other phenothiazine derivatives have been less $\stackrel{c}{\Rightarrow}$ thoroughly investigated. In general, their clinical $\stackrel{5}{+}$ effects are similar to those of the prototype ando dosages are roughly parallel, with the exception of $\frac{}{0}$ acetylpromazine, which is reported to be of about $\frac{\bar{s}}{\frac{1}{7}}$ twice the strength of chlorpromazine.

Promazine is apparently less toxic than chlor- ڤ) promazine and so far no cases of jaundice have $\vec{\oplus}$ been described. On high dosages (about I,400 mg. daily) generalized tremor has been reported $\vec{\omega}$ (Mangun and Webb, 1956), while epileptiform fits $\stackrel{\omega}{\circ}$ have occurred in some cases (Voegele and May, $\mathbb{0}$ 1957) and one instance of agranulocytosis is 3 . recorded. Promazine seems especially useful in $\omega_{\omega}^{\omega}$ the management of the withdrawal symptoms of $\omega$ alcoholism (Mitchell, 1956), where it has the $\stackrel{\infty}{\perp}$ advantage of absence of liver toxicity, and it is in general an acceptable substitute for chlorpro-o mazine.

Mepazine (pacatal) has evoked a number of contradictory reports. Besides a high proportion $\bigcirc$ of side-effects, including dryness of the mouth, $\frac{\overrightarrow{0}}{0}$ constipation, hypotonia and difficulty in visual accommodation, the occurrence of jaundice ang $\vec{c}$ agranulocytosis has led some authors to emphasigec the need for caution in its use (Mitchell et at;; 1957). On the other hand, several workers (e. Bowes, 1956) consider that pacatal is an effective alternative to chlorpromazine in cases which doō not respond to the latter drug.

Acetylpromazine is a relative newcomer and $\stackrel{\AA}{\circledR}$ there are few reports about it at present. Its $\overrightarrow{\vec{O}}$ indications are those of the other phenothiazines, $Э$ but it is possibly less toxic.

Reserpine, chemically unrelated to the phenothiazines, is one of several alkaloids isolated fromo the root of a plant, Rauwolfia serpentina. There 3 . have been many controlled studies on reserpineand from these it appears that it is of little use in: neuroses (Davies and Shepherd, 1955; Folksono and May, 1955), its main indications being the restless aggressive over-active behaviour of psy-음 chotics (e.g. Wing, 1956; Lieberman and $>$ Vaughan, 1957). Although the majority of opinion concedes the value of reserpine in the management of disturbed psychotic patients, some workers (e.g. Penman and Dredge, 1956) conclude it has little 0 effect, but there is fairly general agreement that $\omega$ it does not influence the underlying psychotic process.

The initial dosage of reserpine varies with the individual patient. There is a lag of three to five ${ }^{\text {? }}$ days before full effects are felt with oral doses, but ${ }^{\top}$ intramuscular injection of 5 to ro $\mathrm{mg}$. usually. 


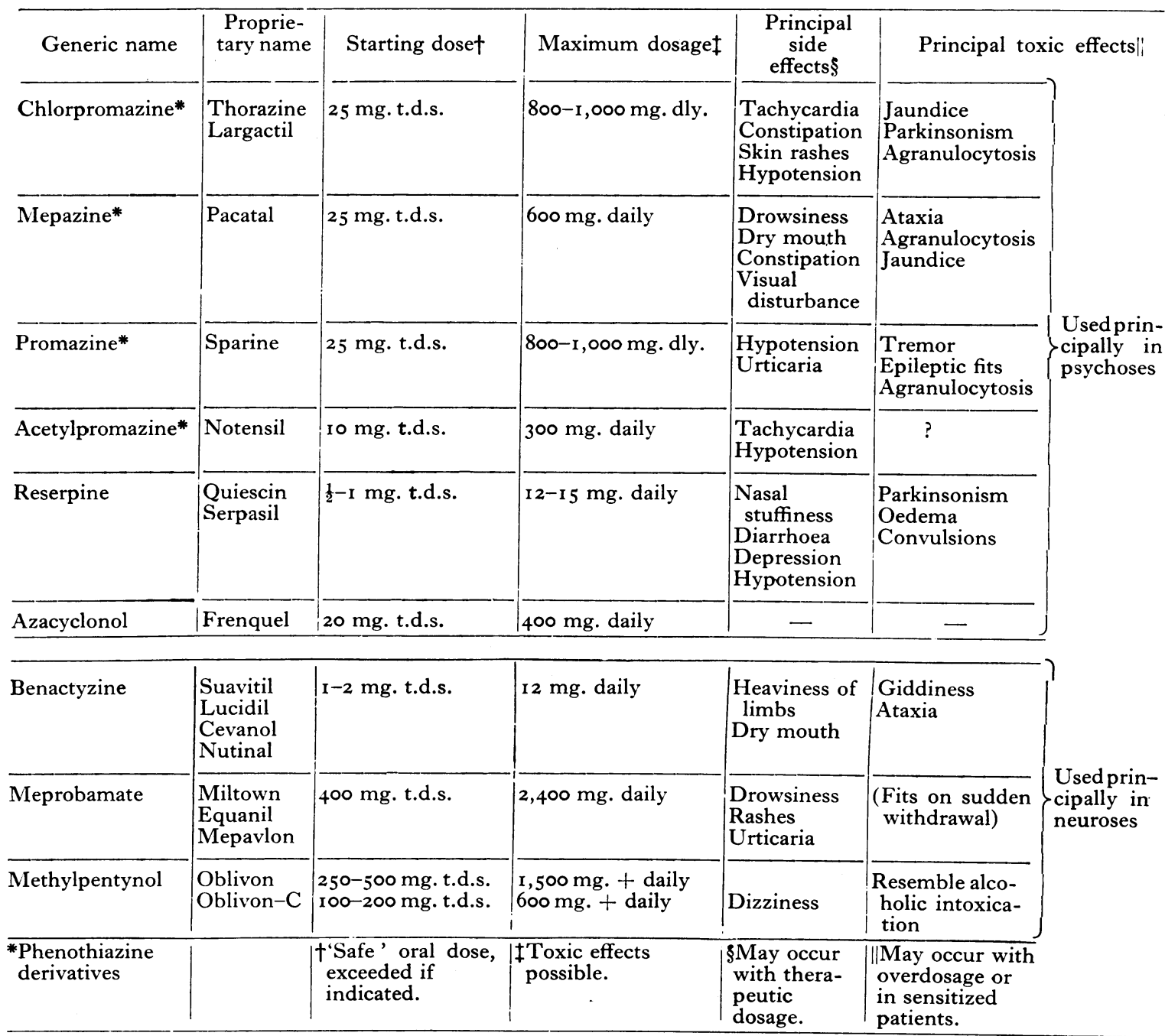

controls aggressive and violent behaviour within 24 hours. It is necessary to press dosage to the maximum to achieve the best results and this may involve giving up to $8 \mathrm{mg}$. daily by mouth (Freeman et al., 1956). Some patients pass through a 'turbulent phase' early in treatment, when overactivity and restlessness may be temporarily increased, but this usually subsides in a few days and the drug need not be reduced (Barsa and Kline, 1956a). Depression, sometimes of suicidal intensity, may complicate reserpine therapy and has occurred in some patients even with low dosages. Ritalin, or E.C.T. in severe cases, may be required to control the depression and the drug should be discontinued. This depressive reaction suggests that reserpine is of value in manic excitement and it has proved possible to abort attacks in patients subject to recurrent episodes. Other side reactions of reserpine include drowsiness, dizziness, diarrhoea, hypotension and nasal stuffiness. Excess salivation may be controlled by tinct. belladonna. More severe effects, which may arise with heavier and prolonged dosage, are Parkinsonism, oedema of the face and feet and convulsive seizures. It appears that reserpine modifies the effect of E.C.T. (Ferguson, 1956) and fatalities have occurred with this combination of treatment (Bracha and Hes, I956).

Reserpine combined with chlorpromazine, in the proportion of $\mathrm{I} \mathrm{mg}$. to $100 \mathrm{mg}$. respectively, is considered by some authors (e.g. Tuteur, 1955) superior to reserpine alone, since the drugs appear to act synergistically and undesirable side-effects are reduced owing to the lower therapeutic dosages required.

Azacyclonol (frenquel) is only just becoming 
available in this country and American reports are contradictory. Fabing (1955b) described its effect in blocking the development of LSD and mescaline psychosis, and particularly in counteracting hallucinations. Subsequent reports (Fabing and Hawkins, 1955; Rinaldi et al., 1955) indicated its possible use in controlling behaviour in disturbed schizophrenic patients by reducing the intensity of hallucinations and delusions, but later studies (e.g. Barsa and Kline, 1956b) have failed to show that it has any therapeutic effect. Sargant (1956) suggests that frenquel may be of use in some cases of intractable depression when combined with E.C.T. All authors agree on the absence of toxicity and side-effects.

\section{Less Powerful Tranquillizers}

Meprobamate acts on the central nervous system only without affecting autonomic functions. Its main effect seems to be the alleviation of anxiety and tension, and it also functions as a muscle relaxant. In America, under the name of 'Miltown,' it enjoys a tremendous vogue as a tranquillizer and encouraging reports of its use in neurotic patients have been summarized by Berger (1956). It is suggested that meprobamate is more effective than barbiturates in the relief of anxiety and tension (Borrus, 1955; Selling, 1955), but this is not supported by West and da Fonseca (1956), who found no marked difference in a controlled trial. It appears that considerable care is necessary in selection of cases, as in some individuals tension is actually increased (Folkson, 1957). Early reports stressed the low toxicity of meprobamate, but this has recently been refuted (Brit. med. F., 1956). Skin lesions, sometimes of a purpuric nature, are known to occur, while drowsiness may be a serious matter in patients driving a car. The sense of euphoria produced in some patients may encourage addiction and overdosage, with signs of intoxication, dysarthria and inco-ordination, and withdrawal after large doses may lead to convulsions (Lemere, 1956).

Benactyzine has anti-cholinergic properties and is believed to block certain afferent pathways, thus protecting higher centres of the brain against external stress. It is said to be of benefit in the relief of anxiety and tension (e.g. Davies, 1956). Some workers, however, state that benactyzine has no advantage over inert tablets (Forbes and Earle, 1957) and the favourable conclusions drawn from a controlled trial by Hargreaves et al. (1957) have been severely criticized by Hare (1957) and Taylor (1957). General experience suggests that benactyzine is of very limited use as a tranquillizer. 'Heaviness' of the limbs, drowsiness and dryness of the mouth have been reported as side-effects.

Methylpentynol is a higher alcohol, which acts as a central nervous depressant and is a mild sedative. Its effect is short-lived, though the carbamate has 3 a more prolonged action. It is said to allay anxiety, $\stackrel{\triangleright}{\varnothing}$ but its use is probably limited to the relief of mild $C$ physiological anxiety and its principal drawback is $\vec{F}$ its short duration of action. Recently Marley and $\stackrel{0}{+}$ Chambers (1956) have drawn attention to its potential toxicity and describe a clinical picture $\frac{\overline{0}}{\mathrm{~N}}$ resembling acute alcoholic intoxication, which in $\vec{\sigma}$ some cases may result from ingestion of only small $a$ quantities of the drug.

\section{Discussion}

It is apparent that the tranquillizing drugs are in $\vec{\omega}$ different stages of evaluation and it is impossible $\frac{\rho}{0}$ to state categorically the clinical indications for all $\frac{0}{3}$ of them with any certainty.

The difficulties of assessment arise out of lack of $\omega$ precision in the measurement of symptomatic and $\omega_{\infty}^{\omega}$ behavioural changes, which must be largely sub- + jective and liable to bias. Even 'double-blind 'o trials are to some extent invalidated by the dis-o tinctive side-effects of many drugs, and the favourable reaction of patients to inert placebo tablets $\overrightarrow{0}$ increases the difficulty of obtaining adequate control material.

The psycho-sociological implications of tranquillizer therapy have been recently discussed $\overrightarrow{0}$ Szasz (1957), who suggests that the drugs function in essence as chemical straitjackets, and thus peop other than those who receive the drug are, in fact, being treated. The danger of such chemical restraint lies in the tolerance with which it is accepted by society, although it may not be in the $\frac{2}{\square}$ best interests of the patient. Dickel and Dixon $\stackrel{2}{\Rightarrow}$ (1957) have drawn attention to a recent change in attitude of society, which has developed a phil- $\frac{3}{5}$ osophy that intimates that fear and anxiety are evidence of illness and necessitate therapy, despite the fact that these and the allied emotions of tension 3 and worry have been, and always will be, important:elements in the shaping of progress and the 3 . development of personality. These authors also stress the danger to the patient's physical andફ emotional health. They studied the effect of tran-o quillizers in 8,200 patients with anxiety as the main symptom and found, besides allergic phe-은 nomena, habituation and other severe physical symptoms, that in 20 per cent. of cases serious - r emotional problems were created in essentially normal people.

The indiscriminate use of these drugs is a matter 0 for concern. Apart from the cost, the dangers of toxicity and the paucity in many cases of adequate clinical trials constitute good reason for a cautious? and questioning attitude (Lancet, 1957; Ministry of Health, 1957).

The present drugs are only forerunners of many 
more to come. Research over a period of time will alone provide a proper perspective in each case and, in the meantime, general prescription of tranquillizers should be limited to those which have been extensively tested and reported upon and where the toxic effects are known and can be anticipated.

\section{Conclusion}

The phenothiazine tranquillizers and reserpine are valuable drugs in psychotic illness, particularly in the management and control of over-active aggressive behaviour and the confusion and excitement of the acutely disturbed patient. There is as yet little evidence that they influence the underlying psychotic process.

Certain drugs, notably chlorpromazine and meprobamate, appear to reduce tension in neurotic patients, but, in general, the effect of current tranquillizers on these patients is disappointing and barbiturates are probably as effective in controlling symptoms.

The toxic reactions produced by tranquillizing drugs vary in severity, but it is wise to regard all as potentially dangerous, certainly during the early stages of their introduction.

As with most new drugs, initial assessments of the value of tranquillizers have tended to be overrated. Uncritical enthusiasm harbours dangers as well as disappointments and in many cases proper evaluation of these drugs must be deferred pending adequate clinical experience.

\section{BIBLIOGRAPHY}

AYD, F. J. (1956), F. nerv. ment. Dis., 124, 84.

BARSA, J. A., and KLINE, N. S. (1956a), Amer. F. Psychiat., BARSA, J. A., and KLINE, N. S. (1956b), Amer. F. Psychiat.,

BERGER, F. M. (1956), Int. Rec. Med. G.P. Clin., 169, 184. BIRD, E. G., GOSS, J. D., and DENBER, H. C. B. (1955), Amer. Ұ.'Psychiat., III, 930.

BOARDMAN, R. H., LOMAS, J., and MARKOWE, M. (1956), Lancet, ii, 487.

BORRUS, J. C. (1955), F. Amer. med. Ass., 157, 1596.

BOWES, H. A. (1956), Amer. F. Psychiat., 113, 530.

BRACHA, S., and HES, J. P. (1956), Amer. F. Psychiat., 113, 257. Brit. med. F. (1956), ii, 1227.

COHEN, I. M. (1956), Amer. F. Psychiat., 113, 115.
DAVIES, D. L., and SHEPHERD, M. (1955), Lancet, ii, 117 . ొֶ

DAVIES, E. B. (1956), Brit. med. .7., i, 480. DICKEL, H. A., and DIXON, H. H. (1957), F. Amer. med. Ass.

FABING, H. D. (1955a), F. Amer. med. Ass., 158, 1461 .

FABING, H. D. (1955b), Neurology, 5, 603.

FABING, H. D., and HAWKINS, J. R. (1955), Dis. nerv. Syst. 16, 329.

FERGUSON, R. S. (1956), f. ment. Sci., 102, 826.

FOLKSON, A., and MAY, A. R. (1955), Brit. med. f., ii, 1121 .

FOLKSON, A. (1957), $\mathcal{F}$. ment. Sci., in press.

FORBES, H. S., and EARLE, B. V. (1957), Brit. med. f., i, 226.

FREEMAN, H., ARNOLD, A. L., and CLINE, H. S. (1956)ด Dis. nerv. Syst., $17,213$.

GADDUM, J. H. (1953), F. Physiol., 121, Ib.

GARMANY G MAY, A R, and FOLKSON, A (1954), Brit med. F., ii, 439 .

HARE, E. H. (1957), Brit. med. F., i, 582.

HARGREAVES, G. R., HAMILTON, M., and ROBERTS, J. M. (1957), Brit. med. F., i, 306.

HIMWICH, H. E. (1955), f. nerv. ment. Dis., 122, $4 \mathrm{I} 3$.

HIMWICH, H. E., RINALDI, F., and WILSON, D. (1956), F. nerv. ment. Dis., 124, 53.

JASPER, H. H. (1949), E.E.G. and Clin. Neurophysiol., 1, 405. KINROSS-WRIGHT, V., and MOYER, J. H. (1956), Arch: Neurol. Psychiat. (Chicago), 76, 675.

LABHARDT, F. (1954), Schweiz. Arch. Neurol. Psychiat., 73, 309. Lancet (1957), i, 308 .

LEMERE, F. (1956), Arch. Neurol. Psychiat. (Chicago), 76, 205. O

LIEBERMAN, D. M., and VAUGHAN, G. F. (1956), Practitioner I77, 632 .

LIEBERMAN, D. M., and VAUGHAN, G. F. (1957), f. ment. Sci. 103, 1 IO.

LOMAS, J. (1955), Brit. med. F., i, 879. MARLEY, E., and CHAMBERS, J. S. W. (1956), Brit. med. $\mathcal{F}$., ii 1467.

MITCHELLL, E. H. (1956), f. Amer. med. Ass., 161, 44.

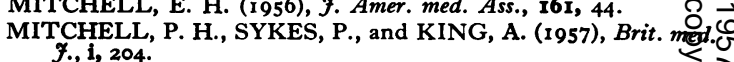

MINISTRY OF HEALTH (1957), Prescribers Notes, 11, 4I.

MORUZZI, G., and MAGOUN, H. W. (1949), E.E.G. and Com. Neurophysiol., 1, 455.

PENMAN, A. S., and DREDGE, T. E. (1956), Arch. Neurol. Psychiat. (Chicago), 76, 42.

RINALDI, F., and HIMWICH, H. E. (1955), Dis. nerv. Syst. ํㅐ I6, I33. ${ }^{13}$., RUDY, L. H., and HIMWICH, H. E. (1955) Amer.' F. 'Psychiat., 112, 345 .

SARGANT, W. (1956), Brit. med. F., i, 939.

SELLING, L. S. (1955), F. Amer. med. Ass., 157, 1594.

SZASZ, T. S. (1957), Arch. Neurol. Psychiat. (Chicago), 77, 86.

TAYLOR, F. K. (1957), Brit. med. f., i, 1006.

TUTEUR, W. (1955), Amer. F. Psychiat., 112, 206

VOEGELE, G. E., and MAY, R. H. (1957), Amer. F. Psychiat. $113,656$.

WEST, E. D., and da FONSECA, A. F. (1956), Brit. med. $7 . \stackrel{3}{3}$ ii, 1206.

WING, L. (1956), f. ment. Sci., 102, 530.

WOOLEY, D. W., and SHAW, E. (1954a), Proc. nat. Acad. Sci., 40, 228.

WOOLEY, D. W., and SHAW, E. (1954b), Brit. med. F., 2, 122.

\section{NOTICE OF SPECIAL INTEREST TO SUBSCRIBERS:} 'WHY NOT HAVE YOUR COPIES OF THIS
JOURNAL BOUND INTO YEARLY VOLUMES?'

You can have your twelve monthly issues fully bound in dark green pin head cloth. lettered in gili on spine with name of Journal, Volume Number and year, complete with index at front, for 21s. Od. post free. A limited number of out of print journals are available to bind into volumes and inake your library complete. Price on application giving decails of issues required to complete back volumes.

THE FELLOWSHIP OF POSTGRADUATE MEDICINE 60 PORTLAND PLACE, LONDON, W.I
WHY NOT

HAVE YOUR

JOURNALS

BOUND? 